\title{
Disaster Management in Pakistan
}

\begin{abstract}
Pakistan's largest metropolis and economic hub, Karachi, surrounded by numerous tectonically active faults, is ill-equipped to cope with seismic hazards. The city is vulnerable mainly due to inadequate construction techniques, lack of awareness, political will and scant historical seismic data. The existing disaster management policies often remain ineffective or unimplemented due to technical or financial constraints, shortage of trained personnel and weak information sharing mechanisms. This research identifies such challenges in Karachi and explores global disaster risk reduction initiatives from better prepared countries; whose implementation feasibility is assessed based on local economic, social, topographical and political circumstances, also presenting a rationale against each methodology. Shortlisting five fundamental aspects of disaster risk reduction, a multi-prong strategy is devised, addressing Karachi's vulnerability and exposure for both urban communities and slums. An Earthquake Early Warning system model using Cell Broadcast technology is formulated, proposing to supplement the existing upgradable seismic network in Pakistan. This and other priority measures constituting the proposed strategy present a customized pragmatic approach of shifting from an emergency response paradigm towards prevention, mitigation and preparedness.
\end{abstract}

\section{Keywords chosen from ICE publishing list}

1. Disaster engineering

2. Seismic engineering

3. Developing countries

4. Sustainability

\section{List of Figures}

Figure 1. From Hazards to Disasters [Source (UN \& WB 2010)]

Figure 2. Disasters vs. deaths in Pakistan [Source (EM-DAT 2014b)]

Figure 3. Tectonic boundaries near Karachi [Source (Hamid et al. 2013)]

Figure 4. Earthquakes greater than magnitude 5.0 occurring within $400 \mathrm{~km}$ of Karachi (19002014) [Source (USGS 2014)]

Figure 5. Survey results on public preparedness for earthquakes 
Figure 6. Survey responses from general public in Pakistan

Figure 7. Survey results. Public response country-wide

Figure 8. Core elements of Multi Prong Strategy

Figure 9. Seismic waves [Source (BGS 2013)]

Figure 10. PMD Broadband seismic monitoring network [Source (Shahid 2011)]

Figure 11. EEWS model for Karachi [Adapted from (Wickramasinghe 2010; Celltick 2013)]

Figure 12. Legal Process for EEWS

Figure 13. Typical two-storey school building in Karachi [Source (Qadir 2012)]

Figure 14. Orangi town [Source (Hasan \& Mohib 1998)]

Figure 15. Awareness, education and training [Source (WMO et al. 2011)]

Figure 16. Multi Prong Strategy 


\section{Introduction}

Disaster risk reduction and sustainable development are essentially each other's prerequisites (Pandey \& Okazaki 2005). According to United Nations International Strategy for Disaster Reduction, there is nothing called 'natural' disasters, only natural hazards. Disasters often follow natural hazards depending on the choices and actions taken today that make us more vulnerable or resilient to disasters in future (UNISDR 2013), explained through Figure 1. While it is difficult to thwart some natural hazards like earthquakes, it is all the more important to focus on preventive measures in order to improve resilience, a key element of sustainability.

Pakistan's geographical location makes it highly susceptible to natural hazard events, predominantly floods, cyclones or droughts but it is observed that earthquakes, though relatively rare have been the deadliest of all, as shown in Figure 2 (EM-DAT 2014a). The devastating Kashmir earthquake of 7.6 magnitude in 2005 killed more than 73,000 people, rendered 3.5 million people homeless (ERRA 2006), while causing a huge loss of USD 5.2 billion (NDMA 2007). As a result, several measures were taken including the formation of Federal Relief Commission, Earthquake Reconstruction and Rehabilitation Authority and National Disaster Management Authority (NDMA). However, similar to many other developing countries, the government has predominantly maintained a reactive, emergency response approach to deal with disasters (NDMA 2007).

This research focuses on the seismic preparedness of the country's financial center, the largest, most populous metropolitan city Karachi (23 million). Located just $150 \mathrm{~km}$ east of the triple junction between the mighty Arabian, Indian and Eurasian tectonic plates, active faults menace the city from almost every direction, depicted in Figure 3. With a short historical seismic record, limited instrumental data and relative dormancy of tectonic activity in recent years, Karachi's vulnerability is largely neglected (Bilham et al. 2007). Jolted by an 8.0 magnitude earthquake in 1945, the Makran Subduction Zone produced a destructive tsunami near Karachi, taking 4,000 lives (Pararas-Carayannis 2006). The presence of the ominous belts of seismicity near Karachi and the relentless northward movement of the Indian plate evidently affirm that earthquakes will recur someday, within $100 \mathrm{~km}$ of the city's suburbs (Bilham \& Hough 2006). Refer to Figure 4. Accounting for more than $20 \%$ of the total GDP of Pakistan (CRSS 2011), Karachi's financial stability has a direct impact on the country's overall economic strength.

Ironically, certain worrisome vulnerability inducing factors like unplanned settlements, rapid urbanization, non-conformance of building codes and lack of awareness and responsibility among residents, when coupled with the city's seismic exposure has already created a catastrophic combination. As part of this research, a nation-wide 
online survey was conducted which revealed startling statistics regarding dearth of earthquake safety measures in Karachi, more forbidding than the rest of the country, shown in Figures 5, 6 \& 7 .

Disaster Risk reduction (DRR) being a relatively new concept in Pakistan has certain limitations, primarily, fiscal deficits, technical constraints, shortage of trained human resources, weak information sharing mechanisms, lack of institutional awareness and political stimulus (NDMA 2013). Consequently, the existing strategies and frameworks are ineffective or not amply implemented. Moreover, since catastrophic events like earthquakes are relatively rare and unpredictable, justifying the allocation of funds for prevention and preparedness remains a challenge.

Not only improving from our own past failings, it is rational to learn from global successful initiatives driven from insightful decisions taken in the face of such adversity. This practice can promote a virtuous cycle benefitting governments inexperienced in tackling emergencies while continuously refining the existing DRR models through routine appraisals, arousing hope that fatalities and damage associated with disasters are not inevitable (Atkinson et al. 2012).

Therefore, in the case of Karachi, where a majority of the buildings are structurally unsound and where earthquake drills or awareness campaigns are entirely alien, we turn for guidance to the global leader in earthquake preparedness: Japan. Effective exploitation of technological advancements in Japan has contributed to safer infrastructure, state-of-the-art early warning systems and a resilient population aware of any looming risks. This research also incorporates notable DRR examples from a country closer to Pakistan in terms of geographical and socio-political circumstances: Turkey. Determined to learn from the experiences of other nations, Turkey revised building codes, increased insurance coverage and is constantly endeavoring to improve public awareness (UN \& WB 2010). Furthermore, an early warning model adaptation from Sri Lanka, also being a developing country, constitutes a part of this research. These exemplary precedents serve as abundant seismic risk prevention models to assess their applicability in Karachi.

Which strategic steps need to be taken 'today' to limit the impact of impending earthquakes? To what extent are global DRR practices applicable in Karachi? What are the possible challenges and opportunities of incorporating these measures locally? And how science and engineering can help achieve a culture of preparedness and prevention? These are the fundamental questions this paper aims to address in the context of Karachi. 


\section{Global DRR Enterprises}

As Japan learns from its own grim experiences, Turkey adopts to adapt, learning from other better prepared nations. Briefly, the lessons to learn from both countries are outlined below.

Japan's global leadership in DRR is dominated by its advanced early warning system that provides the most critical one minute to citizens to take cover. Seismic protection technologies and dedication to stringent building codes have led the infrastructure in Japan to be ranked as the sturdiest in the world (Yamasaki 2012). Besides, Japan's tradition of community participation in troubling times has been pivotal in minimizing fatalities. Other impressive approaches include business continuity plans and earthquake insurance program, mitigating economic losses during a catastrophic event (WB \& GFDRR 2012).

Turkey's national Catastrophe Risk Insurance Pool (TCIP) protects homeowners against natural disasters while Istanbul's Seismic Risk Mitigation \& Emergency Preparedness Project (ISMEP) is imparting disaster preparedness training and education to raise awareness (UNDP 2011). Turkey is also benefitting from Japan International Cooperation Agency (JICA) through collaborative technological transfer schemes and through academic projects with Federal Emergency Management Agency (FEMA) (WMO et al. 2011).

It is however noteworthy that there can be no one-size-fits-all system of DRR that is replicable as such in other regions of the world (Yamasaki 2012). For developing countries, the local financial, social and political circumstances must be catered to while taking decisions relevant to DRR. Therefore a comprehensive feasibility analysis of the given worldwide ventures must be conducted sequentially, in order to gauge its adaptability in Karachi.

\section{Feasibility Analysis}

Adaptation of global DRR tactics for a megacity like Karachi requires meticulous emphasis on the city's distinctive characteristics, its complex environment and societal norms. Addressing the challenges and opportunities associated with introducing global initiatives in indigenous circumstances, the suitability is assessed through credible arguments, keeping in mind the key aim of prevention, preparedness and mitigation. 
Adherence to strict building codes
- Gap between building codes legislation and implementation

- Unclear seismic zoning of Karachi

- Corruption in construction industry

Karachi Building Authority's regulations aim to meet safer building standards

While adoption of new seismic guidelines and zoning is vital, the existing weak buildings' stock is way higher than new developments, a far greater threat.

Urgent measures need to be taken to cost-effectively strengthen critical existing structures, hence this approach is not prioritized for the framework.

- Dense seismographic network requirement (Yamasaki 2012), which Karachi currently lacks

- Financial constraints

- Absence of disaster awareness/ response culture among citizens

- Existing $\mathrm{CBCH}$ technological base is a fortunate affirmative

- Majority of Pakistanis have access to a cell phone

- More than $90 \%$ of Pakistanis live within areas that have cell phone coverage (CIA 2014)

- International funding and public awareness programs in progress

\section{- Presence of required $\mathrm{CBCH}$ technology}

- Funding and technical collaborative projects underway with governments of Japan and China, suggesting that EWS can be prioritized. EWS is fundamentally very much practicable in Karachi owing to the progressive telecommunications technology and market base in Pakistan
} 


\begin{tabular}{|c|c|}
\hline \multirow[t]{3}{*}{$\begin{array}{l}\text { Business } \\
\text { Continuity Plans } \\
\text { (BCP) }\end{array}$} & $\begin{array}{l}\text { - Adequate planning and asset management needed to identify critical systems } \\
\text { (Slater 2012) } \\
\text { - Adaptation with changing technology is tricky } \\
\text { - Often a costly enterprise for developing countries }\end{array}$ \\
\hline & $\begin{array}{l}\text { - Post earthquake rapid restoration of businesses } \\
\text { - Employee welfare and salary security } \\
\text { - Economic stability }\end{array}$ \\
\hline & $\begin{array}{l}\text { - Majority of small businesses in developing countries are ad-hoc, self-employed } \\
\text { \& informal, for which structured BCPs are inapt (ILO 2011) } \\
\text { - In most cases, citizens in developing countries prioritize other pressing } \\
\text { concerns than re-starting their jobs (Slater 2012) } \\
\text { Prioritizina more critical issues, BCP is not chosen for the framework }\end{array}$ \\
\hline
\end{tabular}

\begin{tabular}{l|l}
$\begin{array}{l}\text { Seismic } \\
\text { Protection }\end{array}$ & - Some protection methodologies like base isolation, damping systems too costly \\
Technologies & - Socio-behavioral barriers of residents affecting implementation \\
- Huge presence of non/semi-engineered buildings in Karachi \\
- Lack of support and capacity from government authorities
\end{tabular}




\section{Earthquake Insurance Program}

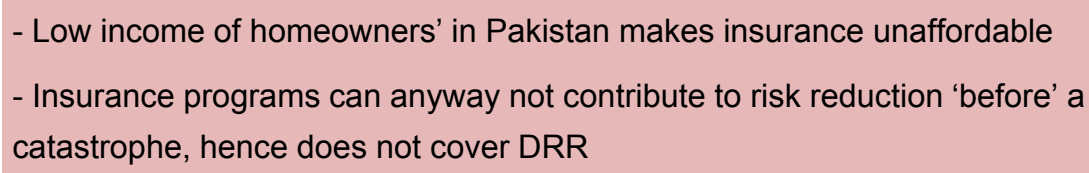

- Disaster risk insurance creates incentives for better recovery by putting a price on risk (WB \& GFDRR 2012)

- As TCIP claims, pecuniary assurance can be provided against earthquake and also for the risks of fire, landslide or tsunami following the earthquake

- Majority of Karachi's population cannot afford insurance schemes

- Essentially it is not a DRR initiative; rather a monetary compensation 'after' the disaster, hence excluded from the proposed framework

\footnotetext{
Community Based Disaster Management (CBDM)

- Communities generally underestimate potential hazards and overestimate their coping capabilities (UNCRD 2004); lack of awareness

- Gender inequality and participation issues

- Religious constraints

- Ethnic or political conflicts in Karachi

- CBDM promotes local, affordable and incremental solutions (UNCRD 2004) - Local community empowerment through involvement at grass-root level

- Culture of self-reliance, responsibility and dignity; encourages creativity and innovativeness (UNCRD 2004)

Suitable approach for Karachi's slums and lower income communities being an economical, self-managed solution through NGOs' technical help and government's assistance. Critical to ensure government's involvement despite CBDM measures. This approach is a vital DRR measure
} 


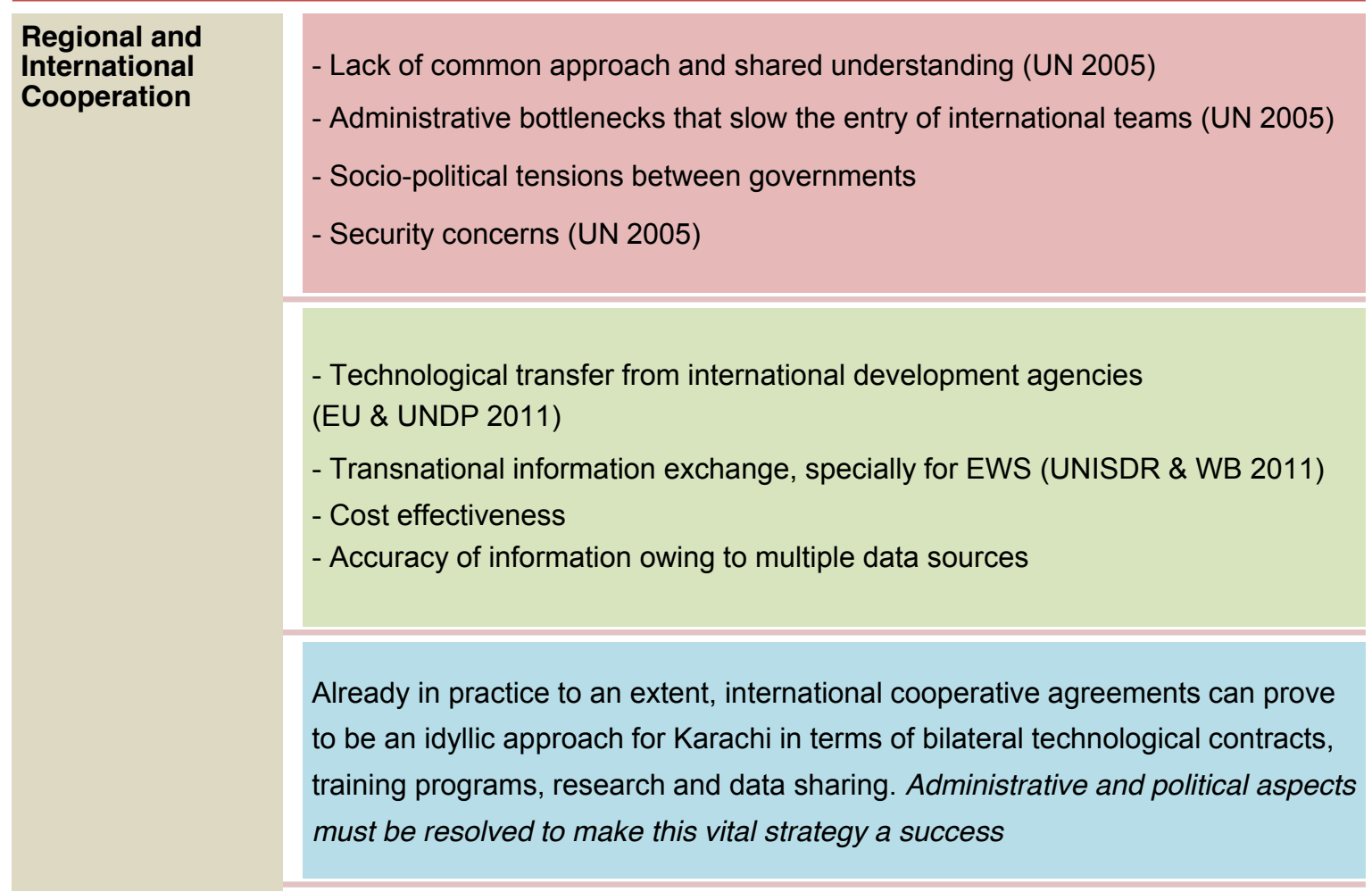

\begin{tabular}{l|l}
\hline $\begin{array}{l}\text { Awareness, } \\
\text { Education and } \\
\text { Training }\end{array}$ & $\begin{array}{l}\text { - Lack of trained resources/ expertise/ implementing partners to impart DRR } \\
\text { training; mostly have experience in response mechanisms (NDMA 2013b) } \\
\text { - Lack of institutional will to initiate awareness campaigns } \\
\text { - Women involvement being a cultural hindrance }\end{array}$ \\
\hline - Enhancement of first-response skills of individuals and organisations (UNCRD \\
2004) \\
- Volunteer training improves civil defense capacity (EU \& UNDP 2011) \\
- Transnational training programs address local shortcomings \\
- Ongoing 'train the trainers' programs are effective \& affordable \\
\hline $\begin{array}{l}\text { None of the DRR strategies can be effective without awareness, education and } \\
\text { training. Knowledge of potential risks and self-help is essential in case of } \\
\text { catastrophes before formal help arrives. This element of DRR holds foremost } \\
\text { importance. }\end{array}$
\end{tabular}


It is impractical to assume standard replication of DRR elements in Karachi which is why a customized conglomeration of the above debated methodologies must be proposed, which addresses the vulnerabilities and exposure of Karachi's slums and urban expanse. The rationale discussed distinctly against each mechanism leads to the shortlisting of a combination of various strategies practically interlinked together. Based on the reasoning, five fundamental aspects of disaster risk reduction are chosen, thereby constituting a Multi-Prong Strategy (MPS), modelled in figure 8, encompassing the overall challenge.

In order to formulate a holistically envisaged solution, the model attempts to present a consolidated blend of technical and non-technical answers combining civil engineering, telecommunications technology, social, political and behavioral principles as well as economic development context.

\section{Multi-Prong Strategy}

As the illustration depicts, three of its core elements; Early Warning System (EWS), Seismic Strengthening of Infrastructure, and Community Based Disaster Management (CBDM) are designed to work in conjunction with awareness creation and collaboration initiatives among relevant local and international bodies. However, sheer formulation of a DRR strategy for Karachi's seismic risks is not the solution. It is therefore necessary to delve further on the modus operandi and to address questions of significance (what, how and who?). Each of the selected five-point agenda is explained through conception, prerequisites, technicalities, application, legalities and funding mechanisms.

\subsection{Early Warning System}

Chiefly idealized from Japan's Earthquake Early Warning System (EEWS) and Sri Lanka's DEWN system, it is a network of seismometers, communication, computers and alarms that is split into two phases: earthquake detection and warning dissemination. Earthquake detection relies on the fact that electronic signals travel faster than seismic waves. The shifting of tectonic plates emits two types of energy, primary (p) and secondary (s) waves. Though released simultaneously, $p$-waves travel relatively quickly, are less powerful and since moving longitudinally, are less destructive than s-waves. This makes early detection of an earthquake possible and critical in order to maximize warning time before the arrival of the harmful s-waves (which oscillate sinusoidally, causing damage to infrastructure and triggering landslides) (Yamasaki 2012). See Figure 9. 
The detection phase requires the presence of a well-established seismic network which includes a combination of i) Seismometers, to detect and differentiate between $p$ - and swaves assisting in the calculation of earthquake's epicenter location and magnitude, ii) Seismic Intensity Meters, to collect maximum seismic intensity to predict degree of shaking and expected damage on ground. It is then the responsibility of disaster agencies to determine whether to broadcast an earthquake warning (Yamasaki 2012).

The warning messages can be disseminated to government officials and general public through outdoor loudspeaker announcements, alert flash messages on television channels, computer pop up warnings, chime tone sounds on FM radio channels and particularly mobile telephone networks (Yamasaki 2012). Though significant financial disparity exists among various social classes in Pakistan, however owing to affordable mobile communication services, the majority of Pakistanis have access to mobile phones. Hence an alert sent on a mobile handset is more likely to be noticed; a preferable choice for Karachi.

\section{Cell Broadcast Technology}

The delivery of detailed warning messages to mobile handsets within a designated geographical area is made possible by the little-known but advanced and proven technology called Cell Broadcast, which sends point-to-area messages, unlike the traditional point-to-point SMS. Designed for simultaneous delivery of messages to multiple users, Cell Broadcast can cover an area as large as the entire telecommunication network or as small as a single cell (GSMA 2013). Since it uses a separate channel to send messages, called Cell Broadcast Channel $(\mathrm{CBCH})$, it has the potential to send warning messages to millions of users in seconds without using additional bandwidth, hence there can be no network congestion.

The time between arrival of $\mathrm{p}$-waves and S-waves (S-P time) is dependent on the proximity to the epicenter location. Once $p$-waves are detected and a warning disseminated, it can give approximately 15-60 seconds warning time to residents located at least $100 \mathrm{kms}$ away from the epicenter; anything within this $100 \mathrm{~km}$-radius is in the blind zone. In 2011, the Sendai area in Japan located $129 \mathrm{~km}$ west of the earthquake's epicenter received a warning 15 seconds prior to the arrival of s-waves, whereas residents in Tokyo (373km away) received alerts 65.1 seconds before ground shaking started (Yamasaki 2012). If millions receive text alerts on their handsets within the first crucial 20 seconds or so, before the arrival of s-waves, it can mean the difference between life and death, an abundant justification for investment of weighty resources and sincere efforts.

Cell Broadcast technology is already available in most mobile handsets (preconfiguration is a prerequisite) and most network infrastructure, so all that subscribers require to do is to activate the functionality for receiving warning alerts (Klein 2007). 
Evidently, CB technology remains the same irrespective of the country where it's applied, thus primarily allowing the same amount of lead time. The process only varies in data collection, recording and transmission where it demands customization.

\subsubsection{EEWS Model for Karachi}

The optimism of implementing a customized adaptation of an early warning system in Karachi stems from the huge scientific potential in Pakistan, owing to the existing technological base and innovation opportunities. The prevalent cell broadcast technology with all mobile operators in Pakistan shimmers confidence in expanding the practical boundaries of Cell Broadcast application to achieve wider objectives. Currently only offering location indicator services (on select handsets), telecom companies are nevertheless equipped to support the government to cultivate this technology further. The lack of adequate number of seismic stations in Karachi however poses the foremost challenge.

Under the jurisdiction of Pakistan Meteorological Department (PMD), a national seismic network comprising broad band, strong motion and short period seismic stations were deployed country-wide through China's and Japan's technical and financial support (Shahid 2011) (Figure 10). Ironically, as per media reports, nearly half of the overall 62 seismometers are not transmitting real time data to the national seismic monitoring network (DAWN 2012), possibly due to lack of funds or maintenance. Moreover, any development initiatives by PMD are only concentrated on digital data processing "after" the occurrence of an earthquake (PMD 2014), entirely overlooking the importance of a few seconds "before" a catastrophe befalls.

This indicates the presence of a rickety backbone for an EEWS which calls for strengthening and up-grading together with the efforts of the government, private sector and communities. With the revival of existing dormant equipment and involvement of mobile network operators, a robust linkage between detection and dissemination phases can be established, enabling this very backbone to start producing results.

An earthquake early warning system for Karachi is thus proposed in this research, wherein the entire system shall work under the umbrella of Pakistan Meteorological Department (PMD). As illustrated in the model (Figure 11), which is an adaptation of Sri Lanka's DEWN system and Japan's EEWS, p-waves are detected by PMD-operated broadband seismic stations and short period sensors installed in or near Karachi and its coastal belt, which record a broad range of frequencies, coupled with seismic intensity data from intensity meters. This collective information is transmitted to the main hub: Regional Seismic Recording Station where the epicenter location and magnitude is 
estimated. Further, this hub is linked with the National Seismic Monitoring System through satellite communication (Magsi 2007). Here this real time data is analyzed to determine whether to broadcast an early warning. Upon verification, the early warning server installed in the National Monitoring System interprets this data to a coherent message format and thereafter, radio cells in the target area are determined where the message needs to be broadcasted. Under directives of Pakistan Telecommunication Authority (PTA), this information is transmitted to all mobile network operators. Thereon, the selected BTS sites in the mobile network start transmitting the message to every mobile phone in the target area using Cell Broadcast Technology.

Without being affected by network congestion, millions of people receive the message at the same time in their own desired language, including visitors from other countries (One2many 2012). In order to remove any possibility of false positives, data recorded from at least two seismic stations is desirable. Usually a warning can be issued at a seismic intensity of $5(\mathrm{~V})$ or greater; however this threshold value is greatly dependent on the structural stability of Karachi's infrastructure.

\subsubsection{Legal and Funding concerns}

Primarily the initiative of National Disaster Management Authority, the seismic network up-grade shall be the responsibility of PMD. In concurrence, PTA would ensure implementation of the early warning system using CB Technology through binding legal agreements with all mobile operators. An exemplary case in this regard is the mandatory condition in Japan for all 3G cellular phones in the market since 2007 to receive Area Mail Disaster Information Service (GSMA 2012). The implementation partners in alliance with mobile network operators will be responsible for instituting the early warning server interface. Illustration of the system is shown in Figure 12.

Earnest collaboration between government agencies, telecommunication operators, seismologists and researchers is indispensable for the successful implementation of this technology. The case of tropical storm in China in 2012 is noteworthy, when the lack of effective coordination between government and mobile operators, rather than any technical challenges led to the failure of warning the wider population about the deadly disaster (GSMA 2012). Moreover, embedding a culture of citizen awareness and knowledge about first response skills is pivotal.

To overcome financial limitations, specialized EWS projects in partnership with China Earthquake Network Center and JICA initiated in the past years, besides multi-donor trust funds are noteworthy precedents. Nonetheless, financial empowerment of local disaster management authorities through the government is evidently crucial. 


\subsection{Seismic Strengthening of Infrastructure}

The plight of seismically vulnerable infrastructure of Karachi suggests approaches that emphasize simple and limited DRR regulations covering only the most at-risk structures. Japan's seismically reinforced buildings are common and performed well after the Great East Japan Earthquake (GEJE) 2011, however for developing countries, a favorable benefit-cost ratio needs to be attained (Kenny 2009). Therefore, expensive strengthening techniques including fiber reinforced polymers, rubber seismic isolation bearings or hydraulic fluid viscous dampers are not considered viable. Relatively inexpensive retrofitting methods using steel or concrete bracings are hence deliberated upon.

\subsubsection{Low-cost retrofit}

Global and indigenous research initiatives aiming to devise affordable retrofitting technologies are encouraging and could facilitate further research (outside the domain of this paper). Worth highlighting is the investigation encompassing cost-benefit comparison conducted by researchers at Columbia University (published in PEB Exchange 2004 - OECD's Program on Educational Building) on a prototype at-risk school building in a developing country. Considering three different retrofit options and assuming a financial value to human life, it proved to be a clear economically desirable choice over entire reconstruction; especially if compared with the potential loss of life (Smyth et al. 2004).

A case study for exploring affordable retrofit solutions locally was conducted at NED University Karachi, incorporating a typical residential-commercial building located in a densely populated area in Karachi. Due to several seismic vulnerabilities, this building was found to be inadequate for seismic zone 4, a high damage risk zone (according to the standards by American Society for Civil Engineers). After examining a number of potential retrofit solutions, the 'rocking spine retrofit option' was recommended. It comprises of an existing spine of infill panels reinforced with shotcrete above a reinforced concrete wall. 'The spine is allowed to rock at the base which reduces large overturning moments from the foundation', thus demonstrating to be an innovative, minimally-intrusive, low-cost solution (NED \& GHI n.d.).

Such research initiatives reaffirm the necessity of conducting seismic vulnerability assessments and to devise economically viable DRR interventions for Karachi. 


\subsubsection{Infrastructure Prioritization and Legal Mechanisms}

Regrettably, the foundation design of telecommunication towers on seismic codes is entirely overlooked in developing countries and Karachi is no exception. The essence of a reliable early warning system is entrusted on a robust telecom infrastructure including rooftop towers and greenfield telecom sites. Although electromagnetic waves having the speed of light travel quicker than seismic p- or s-waves, allowing the warning messages to be delivered even before the possibility of tower collapse, nevertheless, an investigation and subsequent tower-foundation strengthening mechanisms need immediate implementation.

As for buildings in Karachi, they are generally divided into three categories: Nonengineered, Semi-engineered and Engineered. According to Prof. Masood Rafi of NED University Karachi, retrofitting non- and semi-engineered buildings is evidently not feasible as it is highly unaffordable for the tenants (usually from rural suburbs of Karachi) to pay for this 'luxury'. This leads to the realization that only social purpose, engineered buildings in urban areas of Karachi must be considered for such an initiative.

Often in emergencies in Pakistan, among the worst buildings to be damaged are either schools or health facilities, 'indicating the low priority that governments place on their resilience' (UNISDR 2011). Risking lives of a large number of inhabitants, especially children, 'schools' are highly critical social infrastructure demanding special attention (Jain 2004). Seismically vulnerable schools located in Karachi's urban areas, with higher enrolment statistics could possibly be chosen as model demonstration of retrofitting (project execution is possible during the 3-month summer vacation period) using local strengthening techniques (Shaw \& Kobayashi 2001).

Essentially demanding institutional will and dynamic multi-stakeholder involvement, particularly PDMA Sindh, Karachi Building Control Authority and school proprietorship among others, Pakistan must consider the Turkish example where the World Bank finances seismic retrofitting for priority public buildings in Istanbul as part of Istanbul Risk Mitigation and Emergency Preparedness Project (ISMEP). However if masons are trained locally, utilizing indigenous technology, retrofitting could possibly come lighter on the budget which can also sometimes be an initiative of the very community at risk.

\subsection{Community Based Disaster Management}

At the heart of community based disaster management (CBDM) is the principle of community participation, which balances the approach from top-down to incorporating a 
bottom-up participatory attitude. Inducing a sense of ownership and commitment, CBDM empowers communities as direct stakeholders, from the process of policy making to mitigation (UNCRD 2004). Taking lessons from the Great Kobe earthquake in 1995, Japan has now more than 100,000 Community Based Organisations (CBOs) covering more than $60 \%$ families in the entire country. CBOs encourage self-help utilizing resources economically before arrival of professional assistance (Saito 2012).

Although the participation of CBOs before or after an earthquake event in Pakistan is rare, there are success stories of crisis management within Karachi involving urban poor communities contributing towards development projects. One such powerful example is the development of sewerage system in Orangi, one of the largest slums in the world (Figure 14). The Orangi Pilot Project (OPP), the brainchild of the visionary Pakistani social scientist Dr. Akhtar Hameed Khan has helped almost $90 \%$ of the entire settlement to date (residents only pay $50 \%$ of the total cost monthly). It evolved in just a few years to be a 'remarkable self-funded, self-administered and self-maintained grassroots movement relying on nothing more than the resources and skills of its urban poor constituents using local materials and labour in building hundreds of kilometers of extremely low-cost underground sewers' (Zaidi 2001).

Replete with lessons and insights, the OPP model is replicable in the context of disaster preparedness from infrastructure strengthening to appropriate town planning (using seismic hazards interpretation) and imparting earthquake risk awareness via training and education, all this through indigenous community efforts, ending dependence on external support (Zaidi 2001). Linkages must be established with a few existing low-key CBOs, training and equipping them about DRR technicalities through the involvement of NGOs, municipal authorities and research organisations. Particularly, seismic retrofitting of critical buildings including schools or hospitals could prove tremendously affordable owing to CBDM being a non-capital intensive sustainable approach (Shah 2006). CBDM is also ideally suitable for Karachi's massive slum population, where roughly about $55 \%$ of Karachi's total population resides (Rind 2013).

\subsection{Key Supporting Factors}

Evidently, any proposed DRR methodology shall remain ineffective unless these key supplementing factors are incorporated and integrated at every stage: i) awareness, education and training and ii) local and international collaboration mechanisms; further discussed here.

\subsubsection{Awareness, Education and Training}

'Education, training and awareness-raising are cross-cutting elements that strengthen all aspects of disaster risk management at all levels' - from knowledge about first 
response mechanisms to implementing retrofit techniques to skills development of community artisans. Japan's tradition of perpetual awareness about natural hazards was one of the major factors in minimizing the loss of lives during Great East Japan Earthquake (WB \& GFDRR 2012). Replicating the example of Japan, Pakistan's meteorological department can formulate protocols of issuing guidelines to citizens about response mechanisms in case when an earthquake early warning is being disseminated across Karachi. Likewise, training of builders and contractors about retrofitting methodologies and investing in knowledge capitalization at community level for a sustainable CBDM helps in quantification of risks at an early stage.

School curricula particularly need to be revised incorporating modules on disaster preparedness and regular drills must be conducted countrywide. Encouraging research into the field of seismology, Earthquake Engineering is now being taught as a master's degree course at NED University Karachi. Figure 15 lists the potential means of training, education and awareness.

\subsubsection{Local and International Collaboration}

Effective preventive action requires strong collaboration among local and international bodies including government agencies, private corporations, NGOs, academia and communities at large (WB \& GFDRR 2012). In order to maintain institutional capacity in catastrophes, it is essential for Pakistan to gain from technological transfer through UNDP, JICA, the World Bank (WMO et al. 2011) and bilateral cooperative agreements with international governments, especially in the case of strengthening infrastructure and cell broadcast.

For an effective initial response to an early warning, a robust mobile communication network having strong linkages with relevant government agencies is a priority; or it may result in missed opportunities and wasted resources (GSMA 2012). Mobile network operators in Pakistan should maintain conducive relations with PDMA Sindh and Pakistan Meteorological Department for issuing timely alerts in the advent of an earthquake while also avoiding counter-accusations during the process.

It is also worth noting that researchers at NED University, Karachi are already working in collaboration with GeoHazards International (GHI), a California based non-profit organisation, under the Pakistan-US Science and Technology Cooperation Program. The aim is to 'improve Pakistan's capacity for reducing earthquake risks by building the capacity of universities to teach and conduct research in earthquake engineering and to transfer the knowledge needed to seismically retrofit buildings' (Tucker 2011). 
These two important pillars embrace the overall nexus of multi-prong strategy, nestled at the heart of every DRR endeavor.

\section{Strategy Effectiveness}

Just as every region of the world differs socio-economically, their growth towards sustainable development also varies. While professional engineers strive to formulate befitting strategies, searching to fit the perfect niche, a fair share of responsibility also lies on the shoulders of those holding administrative control, down to those directly at risk. For the proposed multi-prong strategy to be effectively implemented, individuals, communities, NGOs, private and government agencies and international collaborators must work together for a mutual cause.

Addressing Karachi's vulnerability and exposure to seismic hazards while underscoring the risk profiles of urban communities and slums, this model attempts to highlight neglected priorities and potential development areas. The four blighting aspects encompassing poor quality construction coupled with rapid unplanned urbanization, dearth of sense of ownership and too little knowledge about the imminent seismic risks are collectively addressed. The discussed five DRR propositions concentrate on overpowering these very shortcomings though not without some major shuffling of our existing systems and modus operandi (Figure 16).

Profound research in order to comprehend the actual risks, ascertaining the trade-offs in decision-making, accepting the limitations and interpreting the findings into realistic DRR initiatives, allocating appropriate human and financial resources and keeping a follow-through as a proposal renders down to practical implementation are benchmarks for this strategy's success.

Prevention and preparedness go a long way in reaping long-term socio-economic benefits as citizens gradually build resilience against natural hazards. The immediate outcome may not present a picture of perfection, nevertheless as the model diagram depicts, the gap between legislation and implementation shall gradually lessen and a culture of social responsibility is likely to flourish.

\section{Discussion}

As earthquakes disregard political boundaries, governments must make informed decisions to cultivate bilateral and multilateral cooperation for mutual benefits. Importantly, data sharing from seismic stations deployed in neighboring countries or 
worldwide could be tremendously profitable in improving early warning accuracy. For optimum utilization and cost-effectiveness, an integrated 'multi-hazard early warning system' should be preferred for Karachi and its coastline. As an immediate action plan, at least the existing non-functional 30 seismometers in other parts of the country need to be operationalized to start recording real time data at the earliest.

In agreement with many researchers, this paper emphasizes embarking initially on small-scale, manageable DRR interventions, doable within the budgetary allowance. Depending on the initial successes strengthening the cause, these projects are steadily up-gradable and up-scalable. Bearing in mind the socio-economic disparities within the city, it is noteworthy that for poorer settlements, relatively costly projects like retrofitting should preferably be delivered through community based strengthening projects, as exemplified by the impressive Orangi Pilot Project (OPP).

It is praiseworthy that the Orangi Project discouraged any donor funding handed in as "aid" regardless of how blighted the squatter settlements were. It is thus stated in conformance with a Water Aid report on OPP (Zaidi 2001), generally donor agencies treat poor communities as objects or victims rather than the actual driving force of their own development, hence stealing away their innate self-esteem. Financial contribution for 'internal' development projects should come from the community itself, relying on what is available from within. That brings to life the true essence of community based interventions.

Worth debating is the idea of relocating the families who inhabit seismically vulnerable, fragile abodes to safer places within Karachi. Seemingly an impractical venture, an inspirational case in point is that of Lyari Expressway Resettlement Project (LERP) in Karachi (2002), commonly said to be the largest urban demolition project for the purpose of road-making in the world. Aimed at relieving traffic congestion in Karachi, the construction of Lyari Expressway involved shifting and resettlement of over 80,000 people and land compensation for relocating to three new developments (GoP 2011). Though with some loopholes and interruptions by powerful interests, it was adequately planned, financed and executed jointly by the federal, provincial and city district governments. In the context of institutional will and commitment, the LERP serves to be an imitable example for disaster prevention interventions over time, though logically open to constructive debate.

Finally, evaluation frameworks to critically assess the performance of NGOs, government agencies, community organisations and international implementing partners need to be devised which may help ensure transparency in operations, reduce chances of corruption and highlight areas of improvement in future. 


\section{Conclusions}

The five aspects of the proposed strategy seek to provide earthquake risk reduction interventions through addressing Karachi's vulnerabilities and exposure. It is rational to learn from past feats and fiascos for a consistent process of improvement and that is where Japan stands out; decades of research and evolution of preparedness techniques has resulted in a population cognizant of seismic risks and the sturdiest buildings in the world.

Assessing the applicability of earthquake preparedness practices from Japan, Sri Lanka and Turkey, it is justifiable that the prevailing economic and socio-political circumstances in Karachi only allow for selected approaches to be implemented. Developing nations generally have far greater livelihood concerns such as basic healthcare, safe drinking water and food; which hamper sustainable growth in the long run, disengaging the federal government from other vital development issues including disaster management.

It is nonetheless important to consider the immediate or collateral beneficiaries and the level of influence a particular risk prevention approach may have upon the current and future generations. We are in the midst of a huge change where new technologies and prevention methodologies have a potential to grow far beyond conventional ways of preparing and coping with catastrophes e.g. mobile phones can quickly become crisis alert and response channels and individuals can become the first responders.

Cities are however growing far more rapidly compared with our understanding of risks and adaptation to new technologies. High rise construction is increasingly becoming a necessity for urban dwellings, but sensibly, those living at the mercy of dilapidated construction must now choose to rebuild by choice rather than coercion. Empowerment of communities should persist and research must continue in the realms of educational institutions.

Though the evolution towards resilience, like in many developing countries, only requires the laws on paper to be implemented in practice, it demands solemn resolve and validation based on true logic. Just as the 2005 Kashmir earthquake caught the nation unawares, let us not whine and whimper when nature's fury unleashes yet another tragedy while we endlessly keep waiting for a second chance. 


\section{References}

Atkinson, P.P. et al., 2012. Reducing Risks of Future Disasters: Priorities for decision makers, London.

BGS, 2013. How We Measure Earthquakes | British Geological Survey (BGS). Available at: http://www.bgs.ac.uk/discoveringGeology/hazards/earthquakes/howWeMeasureTh em.html [Accessed August 22, 2013].

Bilham, R. et al., 2007. Seismic Hazard in Karachi, Pakistan: Uncertain Past, Uncertain Future. , 78(6), pp.601-613.

Bilham, R. \& Hough, S., 2006. Future Earthquakes on the Indian Subcontinent: Inevitable Hazard, Preventable Risk. South Asian Journal, 12, pp.1-9.

Celltick, 2013. CBC - Celltick. Available at: http://www.celltick.com/products/cbc/ [Accessed August 22, 2013].

CRSS, 2011. Karachi Seething under Violence and Terror,

DAWN, 2012. 30 seismometers not linked to national network - DAWN.COM. Available at: http://beta.dawn.com/news/691852/30-seismometers-not-linked-to-nationalnetwork [Accessed August 13, 2013].

EM-DAT, 2014a. EM-DAT. EM-DAT, country profile. Available at: http://www.emdat.be/result-countryprofile?disgroup=natural\&country=pak\&period=1985\$2014\#top10lists [Accessed October 27, 2014].

EM-DAT, 2014b. Result for Country Profile - Pakistan Natural Disasters. Available at: http://www.emdat.be/result-country-profile [Accessed December 18, 2014].

ERRA, 2006. ERRA ::: Earthquake 2005. website. Available at: http://www.erra.pk/eq2005.asp [Accessed October 30, 2014].

GoP, 2011. Lyari Expressway Resettlement Project. Available at: http://www.lerpkarachi.com.pk/pages/index.php [Accessed August 18, 2013].

GSMA, 2012. Disaster Response: Guidelines for Establishing Effective Collaboration between Mobile Network Operators and Government Agencies .

GSMA, 2013. Mobile Network Public Warning Systems and the Rise of Cell-Broadcast. 
Hamid, G. et al., 2013. Structural and Tectonic Control of Karachi (Pakistan ) and the Possibilities of Seismic Hazards. , 7(2), pp.1-7.

Hasan, A. \& Mohib, M., 1998. The case of Karachi , Pakistan.

Jain, S.K., 2004. Chapter 15: implementing school seismic safety programmes in developing countries.

Kenny, C., 2009. Why Do People Die in Earthquakes? The Costs, Benefits and Institutions of Disaster Risk Reduction in Developing Countries,

Klein, P., 2007. Cell Broadcast Technology for Emergency Alert Notifications,

Magsi, M.A., 2007. A REPORT ON THE SEISMIC ACTIVITIES AND TSUNAMI NUMERICAL MODELLING FOR PAKISTAN, Quetta.

NDMA, 2007. National Disaster Risk Management Framework Pakistan,

NDMA, 2013. National Progress Report on implementation of the Hyogo Framework for Action (2011-2013). , (May), pp.1-55.

NED \& GHI, 6-Storey Mixed Use Building in Karachi: A pilot case study of seismic assessment and retrofit design.

One2many, 2012. Cell Broadcast Emergency Alerts,

Pandey, B. \& Okazaki, K., 2005. Community Based Disaster Management :

Empowering Communities to Cope with Disaster Risks Bishnu Pandey and Kenji

Okazaki. , (Regional Development Dialogue).

Pararas-Carayannis, G., 2006. Pakistan's earthquake and Tsunami Hazards: Potential Impact on Infrastructure, Available at:

http://www.drgeorgepc.com/PakistanEarthquakesTsunamis.pdf [Accessed November 6, 2014].

PMD, 2014. National Seismic \& Tsunami Early Warning Center. Available at: http://www.pmd.gov.pk/seismic/seismicnew/index.html [Accessed August 11, 2013].

Qadir, A., 2012. Typical School Building in Karachi. Available at: https://commons.wikimedia.org/wiki/File:Govt_Boys_Comprehensive_Higher_Seco ndary_School_Azizabad_Karachi,_Pakistan2.JPG [Āccessed August 13, 2013].

Rind, H.M., 2013. Katchi Abadis house half of Karachi's population. Available at: http://www.thenews.com.pk/Todays-News-3-214351-Katchi-Abadis-house-half-ofKarachis-population [Accessed December 9, 2014]. 
Saito, T., 2012. Disaster Management of Local Government in Japan,

Shah, H.C., 2006. The last mile: earthquake risk mitigation assistance in developing countries. Philosophical transactions. Series A, Mathematical, physical, and engineering sciences, 364(1845), pp.2183-9. Available at:

http://www.ncbi.nlm.nih.gov/pubmed/16844655 [Accessed August 15, 2013].

Shahid, M., 2011. National Seismic Monitoring Network of Pakistan Meteorological Department,

Shaw, R. \& Kobayashi, M., 2001. Role of Schools in Creating Earthquake-Safer Environment. In UNCRD. Available at:

http://www.preventionweb.net/files/5342_SesiRoleSchoolsEQSafety.pdf [Accessed October 29, 2014].

Smyth, A.W. et al., 2004. Evaluating Earthquake Retrofitting Measures for Schools: A Cost-Benefit Analysis.

Tucker, B., 2011. Pakistan-U . S . Science and Technology Cooperation Program Final Technical Report.

UN \& WB, 2010. Natural Hazards, Unnatural Disasters,

UNCRD, 2004. Sustainable Community Based Disaster Management (CBDM) Practices in Asia.

UNDP, 2011. Disaster Risk Reduction Capacity Assessment Report - for Turkey, Available at:

http://books.google.com/books?hl=en\&lr=\&id=Lgc32CRpOekC\&oi=fnd\&pg=PR7\&d $\mathrm{q}=U N I T E D+N A T I O N S+D E V E L O P M E N T+P R O G R A M M E \& o t s=X f T A k e d b 2 a \& s i g=5$ hvwbWko-PPXTWIUrTFBZaYHMbs [Accessed July 24, 2013].

UNISDR, 2011. Pakistan cannot risk its future. Available at: http://www.unisdr.org/archive/18085 [Accessed August 14, 2013].

UNISDR, 2013. What is Disaster Risk Reduction? Available at: http://www.unisdr.org/who-we-are/what-is-drr [Accessed July 31, 2013].

USGS, 2014. Earthquakes | USGS. Available at:

http://earthquake.usgs.gov/earthquakes/map/ [Accessed August 22, 2013].

WB \& GFDRR, 2012. The Sendai Report; Managing Disaster Risks for a Resilient Future. 
Wickramasinghe, K., 2010. Role of ICTs in Early Warning of Climate Related

Disasters : A Sri Lankan Case Study Author: Kanchana Wickramasinghe. , (Cdi), pp.1-6.

WMO, UNDP \& EU, 2011. IPA Beneficiary Needs Assessment Turkey,

Yamasaki, E., 2012. What We Can Learn From Japan 's Early Earthquake Warning System.

Zaidi, A., 2001. From the Lane to the City: The Impact of the Orangi Pilot Project's Low Cost Sanitation Model. 